\title{
Michigan Farmers of Color and the Future of Sustainable Food Systems
}

\section{Kimberly N. Carr ${ }^{1,2}$, Vanessa Garcia Polanco ${ }^{3}$, Shakara Tyler 4}

${ }^{1}$ Michigan State University, Center for Regional Food Systems, East Lansing, MI

${ }^{2}$ Michigan State University, Center for Interdisciplinarity, East Lansing, MI

${ }^{3}$ Michigan State University, Department of Community Sustainability, East Lansing, MI

${ }^{4}$ Michigan State University, Department of Philosophy, East Lansing, MI

http://doi.org/10.38126/ISPG170102

Corresponding Author: kncarr17@gmail.com

Keywords: sustainable food systems; agrarian racial and ethnic disparities; sustainability; farmers of color; agriculture; Michigan

\begin{abstract}
Executive Summary: Historically, racial and ethnic disparities in agriculture and the food system experienced by farmers of color (FoC) in the United States and in Michigan stem from an exploitative and racialized agricultural system in which white people have primarily benefited and profited. Sustainable agriculture with a strong orientation toward racial justice can serve as a medium for building more racial equity and transforming our racialized food system. Such a medium ensures that the resources to participate and contribute to a sustainable food system are accessible to everyone, not just those with significant power and resources. Although the Michigan Department of Agriculture and Rural Development is in the initial phases of developing a diversity, equity, and inclusion strategic plan, there is currently no specific plan to support and target FoC. While there are several programs performing this work from grassroot organizations, civic groups, extension services, and others, there is no comprehensive statewide effort to create support systems for FoC in Michigan. To address this issue, we recommend the creation of an incentivized farm program as a way to address agrarian racial and ethnic disparities experienced by FoC and advance an equitable and just sustainable food system within the state of Michigan.
\end{abstract}

\section{Agrarian racial and ethnic disparities}

In the United States, the state of Michigan boasts a highly biodiverse and viable agricultural industry producing over 300 agricultural commodities consisting of $56 \%$ crops and $44 \%$ livestock (MDARD 2011; USDA NASS 2017a). However, the State's impressive diversity in commodities is in stark contrast to the diversity among farmers producing these products. Michigan is home to approximately 47,641 farms supporting 79,404 farmers (USDA NASS 2017a). However, only 1\% (856) of Michigan farmers are farmers of color (FoC; e.g., American Indian/Alaska Native, Asian, Black or African American, or Native Hawaiian/Pacific Islander), while people of color account for $24 \%$ of the state's overall population (US Census 2019; USDA NASS 2017a) (Table 1). Even among this small group, disparities relative to white farmers exist in farm ownership and tenure (e.g., full owner, part owner, or tenant) (USDA NASS 2017a; 2017b; 2017c). FoC are less likely to own their farm and instead work as tenants (Horst and Marion 2018), and demographic gaps continue to widen (Table 1 ).

The precise quantification of disparity between white farmers and FoC is complicated by the data collection, which may lead to an understatement of the observation. Classification of race and ethnicity data for federal reporting is specified by the revised version of the United States Office of Management and Budget (OMB) Directive 15 (OMB 1997). OMB reports that Hispanic/Latinx populations can be of 
any race signifying "ethnicity," rather than a separate racial group (OMB 1997).

Consequently, according to the 2017 Census of Agriculture data, Hispanic/Latinx populations are not identified as a "race," but instead are categorized as an "ethnicity." This means that agricultural census data for Hispanic/Latinx populations as a race does not exist. This poses an ethical dilemma beyond the scope of this memo which warrants further consideration.

Additionally, it is important to note that some Indigenous, or Native American, populations do not refer to themselves as "farmers," but instead use cultural terms (e.g., "earth stewards" or "land protectors") that are in greater alignment with their cultural frameworks (Waller and Reo 2018). Although many cultural terms exist across diverse racial and ethnic groups, for the purposes of this policy memo, we will use "FoC" as a representation of all non-white farmers.

Sustainable agriculture with a strong orientation toward racial justice can serve as a medium for building racial equity and transforming a racialized food system (Cohen and Reynolds 2014). Although there is not a consensus on a single definition of sustainable agriculture, for the purposes of this memo, sustainable agriculture is described as a philosophy and practice that uses a systems approach to address the social, environmental, and economic factors that impact natural, human, and environmental resources, both long-term and for future generations (SAREP n.d.; USDA NAL 2007). According to the 1992 Sustainable Agriculture Treaty developed by several non-governmental organizations during the United Nations Conference on Environment and Development, "agriculture is sustainable when it is ecologically sound, economically viable, socially just, culturally appropriate and based on a holistic scientific approach" (USDA NAL 2007). Moreover, sustainable agriculture is vital in advancing environmental justice and stewardship through reduction in pollution (e.g., water and land) and promotion of food sovereignty (Carlisle et al. 2019; Taylor 2018).

Literature has demonstrated that FoC are more likely to adhere to sustainable agricultural practices such as agroecological crops and organic food production
(Edelman et al. 2014; Fernandez et al. 2013; MinkoffZern 2019). Practices like agroecological farming, a method of ecologically-sound farming that focuses on food production using sustainable methods, reduces food miles, reduces greenhouse gas emissions, and expands sustainable food systems (Edelman et al. 2014; Fernandez et al. 2013). A truly sustainable food system promotes nutrition and food security by strengthening and enhancing socioeconomic factors (e.g., environmental and economic) for subsequent generations (FAO 2018). Furthermore, it ensures that the resources to participate in alternative sustainable food systems, such as grants, market access, and technical assistance, are accessible to everyone, not just those with significant power and resourcestraditionally white male farmers (Slocum 2008).

Historically, racial and ethnic disparities in agriculture and the food system experienced by FoC in the United States and in Michigan stem from an exploitative and racialized agricultural system in which white people have primarily benefited and profited via systematic discrimination, racism, land dispossession, and exclusionary practices (e.g., access to capital, credit, and land ownership)(Carlisle et al. 2019; Horst and Marion 2018; Taylor 2018). As a result, this has created an unjust positional advantage for white people to inherit land and have better access to capital and credit, which in turn leads to disproportionate influence in decision-making processes (Carlisle et al. 2019; Horst and Marion 2018; Taylor 2018). This unequal power dynamic perpetuates disparities and further affects FoC's rights, land ownership, and succession (Horst and Marion 2018; Taylor 2018).

Furthermore, access to capital facilitated by the US Government has not been equitably managed. In landmark United States Department of Agriculture (USDA) class-action lawsuits, Black (Pigford $v$. Glickman 1997), Hispanic/Latinx (Garcia v. Vilsack 2000), and Native American (Keepseagle v. Vilsack 1999) farmers sued the USDA for racial discrimination in allocating farm loans and assistance programs and failure to investigate discrimination claims (Garcia v. Vilsack 2000; Keepseagle v. Vilsack 1999; Pigford v. Glickman 1997). The USDA was found guilty in all cases, resulting in multi-million and multi-billion dollar settlement agreements arranged with each respective party (Feder and Cowan 2013). The confluence of inequitable policies and 
discriminatory program management has resulted in record farmland loss and decreased capital among FoC (Taylor 2018; Tyler and Moore 2013).

The present time offers a unique opportunity to foster a sustainable and equitable food system in which FoC can be more visible and take advantage of the educational and training resources that would benefit their farm operations. We recommend a statelevel policy addressed to the Michigan Department of Agriculture and Rural Development (MDARD). Although MDARD is in the initial phases of developing a diversity, equity, and inclusion (DEI) strategic plan, there is currently no comprehensive plan to support FoC. While there are several programs performing this work from civic groups, extension services, grassroot organizations (e.g., Michigan Food and Farming System, Intertribal Agriculture Council), and others, there is no thorough state-level effort to create institutional and structural support systems for FoC in Michigan.

\section{Policy recommendation}

We recommend that MDARD creates an incentivized farm program as a way to address agrarian racial and ethnic disparities experienced by FoC and advance an equitable sustainable food system within Michigan. An incentivized farm program is characterized as a program that provides incentives, either through financial or technical assistance, to promote and encourage farmers to adhere to sustainable and ecologically-sound practices that are not deleterious to the natural and physical environment and will not deplete natural and environmental resources (USDA NRCS n.d.).

Historically, incentivized farm programs have been developed at the federal level and funded by agencies such as the USDA Natural Resources Conservation Service. These programs aim to assist socially disadvantaged farmers by creating programs such as the Beginning Farmer and Rancher Development Program designed to provide educational, technical and mentoring resources to assist beginning farmers and ranchers (USDA NIFA n.d.). Alternatively, a comprehensive, state-level incentivized farm program that is focused on $\mathrm{FoC}$ and includes criteria for appropriate sustainable agriculture production and monitoring practices (e.g., integrated pest management) can be created by MDARD that specifically targets FoC.
Moreover, using a state-level, as opposed to a federallevel, approach to address sustainable agriculture has been demonstrated to be a more effective strategy in securing increased funding for farmers and protecting farmland. This is highlighted by the successes of the Michigan Agriculture Environmental Assurance Program (MAEAP) (Held 2019). The MAEAP is a voluntary program designed to promote preventative agricultural pollution practices on farms and is funded by fees on nitrogen-based fertilizers and pesticides sold in the state of Michigan (Feldmann et al. 2019; MIFB 2015). With these fees, the State was able to raise $\$ 9$ million of funding for MAEAP (Feldmann et al. 2019). However, MAEAP does not specifically recruit FoC, so does not address the need for inclusive sustainability initiatives. Therefore, a state-level approach targeting FoC has the potential to increase equity, sustainability, and financial capital in Michigan's agriculture. This policy could be enacted by the Michigan Legislature, Michigan Department of Agriculture and Rural Development (MDARD), or Executive Office of the Michigan Governor.

\section{i. Advantages}

A sustainable incentive program that targets FoC would support the development of a measurement and surveillance tool that actively monitors and identifies opportunities and improvements relative to food and agriculture production and environmental stewardship initiatives among FoC. For example, current MDARD incentivized programs such as the Michigan Conservation Reserve Enhancement Program (MI-CREP) and the Farmland and Open Space Preservation Program (MI-FOSPP) do not collect race and ethnicity data on their program applications (MDARD MICREP n.d.; MDARD MIFOSPP n.d.). As an implication, these missing demographic data can hinder any DEI initiatives' ability to monitor need and measure the effective successes or remaining challenges experienced by FoC in Michigan.

Incentivized farm programs, such as conservation and environmental stewardship programs, generally improve access to technical and training resources and promote a more sustainable environment (Hebblethwaite and Somody 2008). State-level efforts via MDARD to support FoC with emphasis on farm biodiversity and improved food production (e.g., via soil and water quality, pesticide, and economic 
risk management) could also be an asset. For example, programs that enable full participation of FoC in the agricultural sector will have broader benefits by concurrently increasing the general use of such beneficial practices across crop types. Additionally, this policy recommendation will initiate the necessary support to encourage $\mathrm{FoC}$ to adhere to sustainable agricultural practices.

State-level efforts aimed at FoC will positively impact Michigan's biodiverse agrculture economy and other sectors due to the permeating benefits of increased capital and a healthier workforce. Also, more robust agricultural research and best environmental management practices may be identified through their more widespread use and data collected through the program's surveillance tools with greater numbers of diverse participants.

\section{ii. Disadvantages}

The primary hurdle for this policy is that funding to support this state-level incentivized farm program may lead to an increase in taxes for Michigan residents. However, MDARD could use fees as it has in the MAEAP program to offset the potential change in taxes. While, stakeholders (e.g., residents) and decision-makers (e.g., legislators) may not view this program as necessary, preferring to rely solely on federal farm programs, we believe such disinterest would be to the detriment of Michigan's agricultural sector.

\section{Conclusion}

According to the most recent Farm Bill FoC are considered to be both historically underserved and socially disadvantaged (US GPO 2018a; US GPO 2018b, USDA NRCS NV 2020). As we seek to reduce structural and historical inequalities for $\mathrm{FoC}$, the policy recommended in this memo will enable FoC to be agents for food security while also building sustainable cities and communities that embrace sustainable agriculture and promote biodiversity. To implement this initiative, strategic leadership and guidance from MDARD are needed to foster policies and programs that will better serve FoC and address agrarian racial and ethnic disparities they experience. 


\section{Appendix: Table 1}

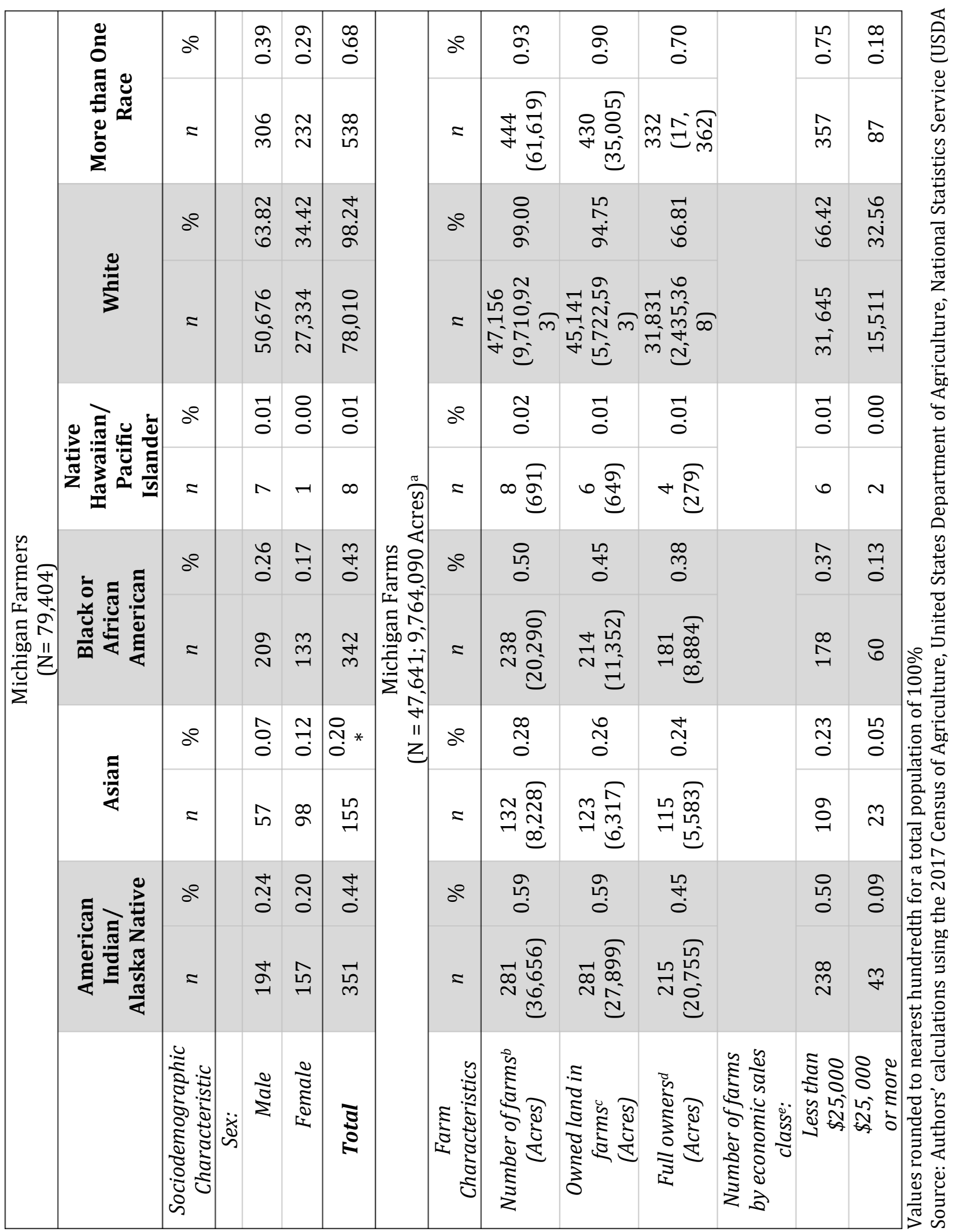




\section{References}

Carlisle, Liz, Maywa de Wit Montenegro, Marcia S. DeLonge, Adam Calo, Christy Getz, Joanna Ory, Katherine Munden-Dixon et al. 2019. "Securing the Future of US Agriculture: The Case for Investing in New Entry Sustainable Farmers." Elementa Science of the Anthropocene 7(1): 17-36. http://doi.org/10.1525/elementa.356.

Cohen, Nevin, and Kristin Reynolds. 2014. "Resource Needs for a Socially Just and Sustainable Urban Agriculture System: Lessons from New York City." Renewable Agriculture and Food Systems 30(1): 103-114. https://dx.doi.org/10.1017/S174217051400021 $\underline{0 .}$

Edelman, Marc, Tony Weis, Amita Baviskar, Saturino Borras Jr, Eric Holt-Gimenez, Deniz Kandiyoti, and Wendy Wolford. 2014. "Introduction: Critical Perspectives on Food Sovereignty." Journal of Peasant Studies 41(6): 911-931. https://doi.org/10.1080/03066150.2014.96356 8.

Feder, C., and T. Cowan. 2013. Garcia v. Vilsack: A policy and legal analysis of a USDA discrimination case. http://nationalaglawcenter.org/wpcontent/uploads/assets/crs/R40988.pdf.

Feldmann, J, Vincent Gauthier, Maggie Monast, Mark Rupp, and Britt Aasmundstad. 2019. Innovative State-Led Efforts to Finance Agricultural Conservation.

https://www.edf.org/sites/default/files/docume nts/innovative-state-led-efforts-financeagricultural-conservation.pdf.

Fernandez, Margarita, Katherine Goodall, Meryl Olson, and Ernesto Mendez. 2013. "Agroecology and Alternative Agri-Food Movement in the United States: Toward a Sustainable Agri-Food System." Journal of Agroecology and Sustainable Food Systems 37(1): 115-126. https://doi.org/10.1080/10440046.2012.73563 $\underline{3 .}$

Food and Agriculture Organization (FAO). 2018. Sustainable food systems: Concept and framework. http://www.fao.org/3/ca2079en/CA2079EN.pdf.

Garcia v. Vilsack, No. 00-2445, (D.D.C. 2000). https://www.clearinghouse.net/chDocs/public/ FH-DC-0010-9000.pdf.

Hebblethwaite, John F, and Carol N. Somody. 2008. "Progress in Best Management Practices." In The Triazine Herbicides: 50 Years Revolutionizing Agriculture, edited by Homer M. LeBaron, Janis E. McFarland and Orvin C. Burnside, 501-517. Elsevier. https://doi.org/10.1016/B978-0-44451167-6.50042-8.
Held, Lisa. 2019. "How States are Helping Farmers Adopt Sustainable Practices." Civil Eats, October 16, 2019. https://civileats.com/2019/10/16/howstates-are-helping-farmers-adopt-sustainablepractices/.

Horst, Megan, and Amy Marion. 2018. "Racial, Ethnic and Gender Inequities in Farmland Ownership and Farming in the U.S." Agriculture and Human Values 36: 1-16. https://doi.org/10.1007/s10460-018-9883-3.

Keepseagle v. Vilsack, No. 99-03119, (D.D.C. 1999). https://www.clearinghouse.net/chDocs/public/ FH-DC-0009-9000.pdf

Michigan Department of Agriculture and Rural Development (MDARD). 2011. Facts About Michigan Agriculture." Accessed April 10, 2020. https://www.michigan.gov/mdard/0,4610,7125-1572-7775--,00.html.

Michigan Department of Agriculture and Rural Development, Michigan Conservation Reserve Enhancement Program (MDARD MICREP). n.d. "Permanent Conservation Easement Program, Landowner Application Form." Last revised August 20, 2001. https://www.michigan.gov/documents/mda laf 9656 7.pdf.

Michigan Department of Agriculture and Rural Development, Farmland and Open Space Preservation Program (MDARD MI FOSPP). n.d. "Farmland and Open Space Preservation Program, Application for Designated Open Space Easement." Last revised October 2017. https://www.michigan.gov/documents/mdard/ Designated Open Space Easement Application 3 61492 7.pdf.

Michigan Farm Bureau (MIFB). 2015. "MAEAP funding measure passes House". May 21, 2015. https://www.michfb.com/mi/news/policy and politics/maeap funding measure passes house/.

Minkoff-Zern, Laura-Anne. 2019. The New American farmer: Immigration, Race and the Struggle for Sustainability. Cambridg: The MIT Press.

Pigford v. Glickman, No. 97-1978 (D.D.C. 1997). https://www.clearinghouse.net/chDocs/public/ FH-DC-0006-9000.pdf.

Slocum, Rachel. 2008. “Thinking Race Through Corporeal Feminist Theory: Divisions and Intimacies at the Minneapolis Farmers' Market." Social \& Cultural Geography 9(8): 849-869. https://doi.org/10.1080/14649360802441465. Sustainable Agriculture Research \& Education Program (SAREP). n.d. What is Sustainable Agriculture?. Accessed August 25, 2020. https://sarep.ucdavis.edu/sustainable-ag. 
Taylor, Dorceta. 2018. "Black Farmers in the USA and Michigan: Longevity, Empowerment and Food sovereignty." Journal of African American Studies 22(2): 49-76. https://doi.org/10.1007/s12111018-9394-8.

Tyler, Shakara S., and Eddie A. Moore. 2013. "Plight of Black Farmers in the Context of USDA Farm Loan Programs: A Research Agenda for the Future." Professional Agricultural Workers Journal 1, no.1 (Article 6):1-11.

https://tuspubs.tuskegee.edu/cgi/viewcontent.c gi? article $=1004 \&$ context $=$ pawj.

United States Census Bureau (US Census). 2019. "Quick Facts Michigan". United States Census Bureau. https://www.census.gov/quickfacts/MI.

United States Department of Agriculture, National Agricultural Library (USDA NAL). 2007.

Sustainable Agriculture: Definitions and Terms, Special Reference Briefs Series no. SRB 99-02. https://www.nal.usda.gov/afsic/sustainableagriculture-definitions-and-terms.

United States Department of Agriculture, National Agricultural Statistics Service (USDA NASS). 2017a. 2017 Census of Agriculture State Profile Michigan. Accessed April 5, 2020. https://www.nass.usda.gov/Publications/AgCen sus/2017/Online Resources/County Profiles/Mi chigan/cp99026.pdf.

United States Department of Agriculture, National Agricultural Statistics Service (USDA NASS). 2017b. Table 61 Selected Farm Characteristics by Race: 2017. Accessed April 5, 2020. http://www.nass.usda.gov/Publications/AgCens us/2017/Full Report/Volume 1, Chapter 1 State Level/Michigan/st26 10061 0061.pdf.

United States Department of Agriculture, National Agricultural Statistics Service (USDA NASS). 2017c. Table 63 Selected Producer Characteristics by Race: 2017. Accessed April 5, 2020.

https://www.nass.usda.gov/Publications/AgCen sus/2017/Full Report/Volume 1, Chapter 1 Stat e Level/Michigan/st26 10063 0063.pdf.
United States Department of Agriculture, National Agricultural Statistics Service (USDA NASS). 2017d. Appendix B. General Explanation and Census of Agriculture Report Form. Accessed August 20, 2020. https://www.nass.usda.gov/Publications/AgCen sus/2017/Full Report/Volume 1, Chapter 1 US/ usappxb.pdf.

United States Department of Agriculture, National Agricultural Statistics Service (USDA NASS). 2020. Farms and Land in Farms 2019 Summary. https://www.nass.usda.gov/Publications/Todays Reports/reports/fnlo0220.pdf.

United States Department of Agriculture, Natural Resources Conservation Service (USDA NRCS). n.d. Incentive Programs and Assistance for Producers. Accessed August 25, 2020.

https://www.nrcs.usda.gov/wps/portal/nrcs/de tail/national/climatechange/resources/?cid=stel prdb1043608.

United States Department of Agriculture, National Institute of Food and Agriculture (USDA NIFA). n.d. Beginning Farmer and Rancher Development Program (BFRDP). Assessed August 25, 2020. https://nifa.usda.gov/fundingopportunity/beginning-farmer-and-rancherdevelopment-program-bfrdp.

United States Department of Agriculture, Natural Resources Conservation Service Nevada (USDA NRCS NV). 2020. Small \& Limited and Beginning Farmers \& Ranchers. https://www.nrcs.usda.gov/wps/portal/nrcs/m ain/nv/about/outreach/slbfr/.

United States Government Publishing Office (US GPO). 2018a. TITLE- 7 AGRICULTURE. https://www.govinfo.gov/content/pkg/USCODE2018-title7/pdf/USCODE-2018-title7-chap55sec2279.pdf.

United States Government Publishing Office (US GPO). 2018b. Agriculture Improvement Act of 2018. https://www.congress.gov/115/bills/hr2/BILLS -115hr2enr.pdf.

Waller, Donald M,, and Nicholas J. Reo. 2018. "First Stewards: Ecological Outcomes of Forest and Wildlife Stewardship by Indigenous Peoples of Wisconsin, USA." Ecology and Society, 23(1): 4559. https://doi.org/10.5751/ES-09865-230145.

Kimberly N. Carr is a postdoctoral research associate and interdisciplinary scholar in both the Center for Regional Food Systems (CRFS) and Center for Interdisciplinarity (C4I) at Michigan State University. CRFS and C4I are positioned in the Department of Community Sustainability and Department of Philosophy. Her interdisciplinary research is in the context of food sovereignty and racial equity in Michigan. 
Vanessa Garcia Polanco is an activist-researcher graduate student in the Department of Community Sustainability at Michigan State University. She is interested in immigrants, refugees, and people of color in agriculture and the food system. She is a board member of Michigan Food and Farming Systems.

Shakara Tyler is a postdoctoral scholar in the Department of Philosophy at Michigan State University (MSU). She has worked with the MSU Center for Regional Food Systems as the Underserved Farmer Development Specialist, where she provided technical assistance to underserved farming groups such as farmers of color, women farmers, and beginning farmers, as well as developed research agendas focused on better supporting these communities. She serves as a board member of the Detroit Black Community Food Security Network (DBCFSN) and Detroit Peoples' Food Co-op (DPFC), and a coordinating member of the Black Dirt Farm Collective (BDFC).

\section{Acknowledgements}

The authors would like to acknowledge Jennifer Silvieri, Director of Operations, Michigan Food and Farming Systems, Dr. Michael O'Rourke, Director, MSU Center for Interdisciplinarity, Rich Pirog, Director, MSU Center for Regional Food Systems, and Dr. Stephanie Vasko, Managing Director, MSU Center for Interdisciplinarity, and members of MSU Scicomm for their feedback and support. 